
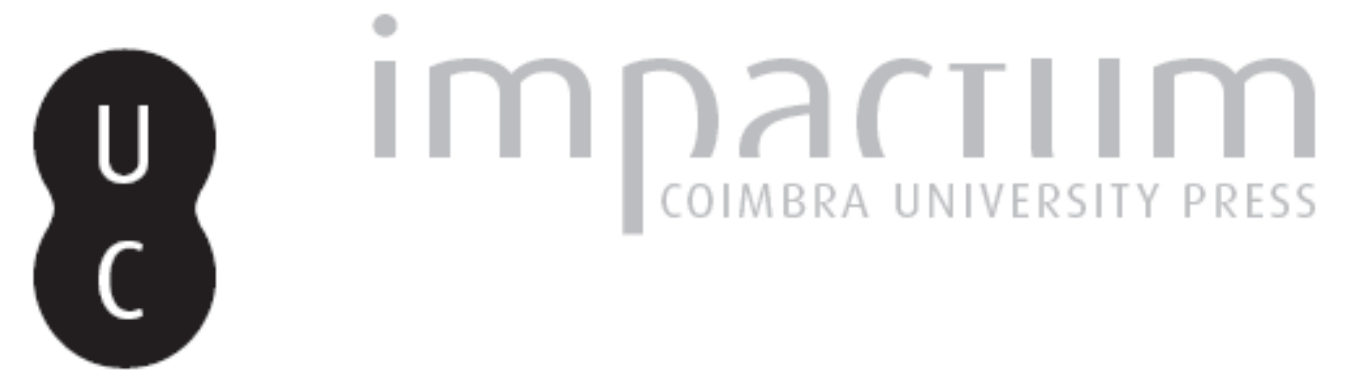

\title{
Riscos naturais na região tropical brasileira
}

Autor(es): Conti, José Bueno

Publicado por: Associação Portuguesa de Riscos, Prevenção e Segurança

URL persistente:

URI:http://hdl.handle.net/10316.2/40089

DOI:

DOI:https://doi.org/10.14195/1647-7723_9_7

Accessed : $\quad$ 26-Apr-2023 16:22:46

A navegação consulta e descarregamento dos títulos inseridos nas Bibliotecas Digitais UC Digitalis, UC Pombalina e UC Impactum, pressupõem a aceitação plena e sem reservas dos Termos e Condições de Uso destas Bibliotecas Digitais, disponíveis em https://digitalis.uc.pt/pt-pt/termos.

Conforme exposto nos referidos Termos e Condições de Uso, o descarregamento de títulos de acesso restrito requer uma licença válida de autorização devendo o utilizador aceder ao(s) documento(s) a partir de um endereço de IP da instituição detentora da supramencionada licença.

Ao utilizador é apenas permitido o descarregamento para uso pessoal, pelo que o emprego do(s) título(s) descarregado(s) para outro fim, designadamente comercial, carece de autorização do respetivo autor ou editor da obra.

Na medida em que todas as obras da UC Digitalis se encontram protegidas pelo Código do Direito de Autor e Direitos Conexos e demais legislação aplicável, toda a cópia, parcial ou total, deste documento, nos casos em que é legalmente admitida, deverá conter ou fazer-se acompanhar por este aviso.

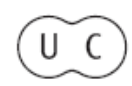




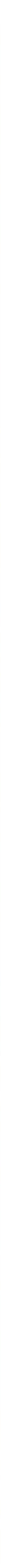




\title{
Riscos naturais na região tropical brasileira
}

\author{
Josê Bueno Conti*
}

\section{Resumo:}

$\mathrm{O}$ artigo procura caracterizar o ambiente tropical e sua especificidade, apresentando, em seguida, exemplos ocorridos no território brasileiro relacionados com excesso ou escassez de chuvas. Mostra episódios catastróficos de cheias no Rio de Janeiro, em Salvador em áreas serranas intensamente desmatadas, além de apontar riscos de desertificação na região semi-árida.

Palavras-chave:

Tropical, precipitação, inundações, desertificação.

\section{Résumé:}

Cet article présente, d'abord, une caractérisation du milieu tropical, et son spécificité, et éxpose, dans la suite, quelques exemples dans le territoire brésilien dus à l'éxcès ou l'insuffisance de pluies. Analyse des événements d'inondations catastrophiques à Rio de Janeiro et Salvador et dans les régions montagneuses très déboisées, ajoutant des cas de risques de désertification dans la région semi-aride.

Mots-clés:

Tropical, précipitation, inondations, désertification.

\section{Abstract:}

This paper brings a tropical environment and its peculiarities, followed by some examples of events related to the amount of rain in the Brazilian territory. It shows some catastophical happenings of inundation that occurred in Rio de Janeiro, Salvador and in nountainous lands, besides of showing risks of desertification in the semi arid zone.

Keys-words:

Tropical, rain, inundation, desertification.

\section{Introdução}

Os riscos naturais, enquanto fenômenos fora do controlo da ação humana, sempre foram objeto de preocupação dos geógrafos, especialmente dos que se consagram ao estudo da geografia da natureza, embora tais ocorrências sejam, muitas vezes, consequência da ação desordenada da sociedade sobre o suporte naturale, portanto, também objeto de interesse da geografia humana.

O Prof. Fernando Rebelo, da Universidade de Coimbra, em sua obra "Riscos Naturais e Ação Antrópica", que trata dos riscos naturais em Portugal, discute a teoria do risco em Geografia, estabelece

\footnotetext{
* Professor Títular do Departamento de Geografia da Faculdade de Filosofia, Letras e Ciências Humanas da Universidade de São Paulo (USP).
}

uma tipologia e, ainda, introduz a noção de bacia de riscos (REBELO, 2001)

A Prof. ${ }^{a}$ Neyde Maria Santos Gonçalves, da Universidade Federal da Baía (Brasil) apresenta a seguinte síntese a respeito do tema: "Os fenômenos do ambiente natural apresentam-se sob a mais variada escala de intensidade. Quando esses eventos tornam-se perigosos para o homem são chamados de riscos ou azares naturais. Portanto um evento extremo torna-se um risco quando supera a capacidade material de determinada organização social para absorver, amortizar ou evitar seus efeitos negativos. Tal situação pode ser desencadeada não só pelo evento extremo mas, também, pelo evento normal e é este o fato que determina o grau de vulnerabilidade da sociedade em questão. O risco, ou seja, a possibilidade de ocorrência do fenômeno, está ligado à capacidade de 
determinada sociedade prever um evento natural cíclico e de a ele ajustar-se, em função do conhecimento de seus parâmetros: frequência, intensidade, duração, recorrência, etc. de vez que os eventos extremos podem ser atenuados, controlados, mas dificilmente evitados. Do ponto de vista social, considera-se, também, catástrofe como sendo aquela situação que supera a capacidade material da população para absorver, atenuar ou evitar os seus efeitos negativos. Neste sentido, o grau de catástrofe está diretamente relacionado com o de vulnerabilidade da sociedade afetada e pode, mesmo, ser ocasionada por um evento natural de magnitude menor, gerando situações evitáveis. A caraterização das catástrofes pressupõem, assim, que a ocorrência dos eventos extremosa possua repercussões humanas, havendo, portanto, uma relação entre a magnitude do evento, os parâmetros sócio-económicos e a vulnerabilidade dos sistemas envolvidos" (GONÇALVES, 1992).

O Prof. Bryant. da Universidade de Cambridge (EUA), em sua obra Natural Hazards, propôs o seguinte quadro para classificar os eventos catastróficos (v. quadro 1):

A civilização urbano-industrial, oriunda e desenvolvida longe dos trópicos, para cá se transferiu e se implantou sem a necessária adptação às características específicas das baías latitudes. A tarefa de ocupar o espaço terrestre de forma adequada constitui um desafio que a sociedade nem sempre tem sabido enfrentarcom acerto, particularmente nas áreas tropicais onde a grande concentração de energia solar torna os processos naturais mais agressivos e incontroláveis.

E não são apenas as grande áreas urbanas que exibem essa desarmonia entre a sociedade e a natureza. No Brasil, vastas extensões de territórios recém-ocupados, porém submetidos a intensos processos de desmatamentos e queimadas para a prática da agricultura ou pecuárias, somadas às atividades mineradoras em grande escala, acabam por se degradar de forma generalizada abrindo caminho para o empobrecimento biológico e a desertificação.

\begin{tabular}{|c|c|c|c|c|c|c|c|c|c|c|}
\hline \multicolumn{11}{|c|}{ GRADUAÇÃO DAS CARACTERÍSTICAS E IMPACTOS } \\
\hline Ordem & Evento & $\begin{array}{c}\text { Grau } \\
\text { de } \\
\text { severidade }\end{array}$ & $\begin{array}{l}\text { Tempo de } \\
\text { Duração } \\
\text { do evento }\end{array}$ & $\begin{array}{c}\text { Extensão } \\
\text { do evento } \\
\text { (área) }\end{array}$ & $\begin{array}{l}\text { Perdas } \\
\text { de } \\
\text { vida }\end{array}$ & $\begin{array}{c}\text { Perdas } \\
\text { econômicas }\end{array}$ & $\begin{array}{l}\text { Efeito } \\
\text { social }\end{array}$ & $\begin{array}{l}\text { Impacto } \\
\text { de longo } \\
\text { prazo }\end{array}$ & $\begin{array}{l}\text { Extensão de } \\
\text { tempo (grau } \\
\text { de surpresa) }\end{array}$ & $\begin{array}{l}\text { Ocorrência } \\
\text { catástrofe } \\
\text { associadas }\end{array}$ \\
\hline$\because \because \because$ & Secalestiagem $\because$ & $\because \because \div$ & $\because \because \because \because$ & $\because \cdots$ & $\because 6$ & & $\because \div$ & $\because \because$ & $\because \because$ & \\
\hline$\because 2$ & Gicing tringas $\because$ & $\because \because \because$ & $\because \therefore \therefore$ & $\because \because \because$ & $\because \because \because$ & $\because 2 \because$ & $\because \because$ & $\because 6$ & $\because 6 \%$ & $\because 6$ \\
\hline$\because 3 \because 6$ & 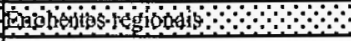 & $\because \because \because \because$ & $\because \because 2 \because$ & 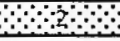 & $\therefore$ & 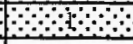 & $\because \because$ & $\because 2$ & $\because 4 \because$ & $\because \because$ \\
\hline 4 & terremotos & 1 & 5 & 1 & 2 & 1 & 1 & 2 & 3 & 3 \\
\hline 5 & Erups & 1 & 4 & se & 2 & se & 2 & & 3 & 1 \\
\hline$\because 6 \%$ & Ter & $\because \because \because$ & $\because 6$ & $\because \because 6$ & $\because 6$ & $\because \because 3$ & $\because 2$ & $\because 2 \because$ & $\because \because \because$ & $\because \because 6$ \\
\hline$\%$ & Lstrahil $\Leftrightarrow$ & $\because \because$ & $\because 4$ & $\because \because$ & $\because 2$ & $\because 2 \because 3$ & $\because$ & $\because 6$ & $\because 4$ & $\because 5 \because \because$ \\
\hline$\because \mathrm{B}$ & decinatas & $\because \because \because$ & $\therefore \because \cdots$ & $\because 6$ & $\because \because \because$ & $\because \because \because$ & $\because 3$ & $\because \because 3$ & $\because \because$ & $\because \because \because \because \because$ \\
\hline 9 & Expansão dos solos & 5 & 1 & 1 & 5 & 4 & 5 & 3 & 1 & 5 \\
\hline$\because 6$ & 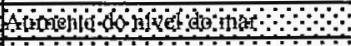 & $\because \because \because$ & $\because \because \because$ & $\because \because 9$ & $\because \because 6$ & $\because 3 \%$ & $\because \because \because$ & $\because \because$ & $\because \because 5 \%$ & $\because 64 \%$ \\
\hline$\because 1$ & cebei & $\because \because$ & $\because \because$ & $\because \because$ & $\because \because$ & $\because 4:$ & $\because:$ & $\because 3$ & $\because 2$ & $\because \cdots$ \\
\hline$\because 2$ & tonestodestearea & $\because 3 \because$ & $\because 3$ & $\because \because \because$ & $\because 6 \because$ & $\because \because \cdots$ & $\because 5 \%$ & $\because 4$ & $\because \because$ & $\because \because \cdots$ \\
\hline$\because 13$ & Deslizaldeto & $\because 4 \because$ & 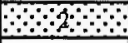 & $\because \because \because \because$ & $\because \because 4 \div$ & $\because \because 4 \because \because$ & $\because 4 \%$ & $\because \because \because$ & $\because \because \therefore \because 6$ & $\because \because 6 \%$ \\
\hline 14 & Erosão praial & 5 & 2 & 2 & 5 & 4 & 4 & 4 & 2 & 5 \\
\hline$\because 15 \%$ & Escophosdequala & $\because 2$ & $\because \because$ & $\because \because$ & $\because 3$ & $\because \because \%$ & $\because$ & $\because 6$ & $\because$ & $\because 5:$ \\
\hline 16 & Movin & 5 & 1. & 2 & 5 & 4 & 5 & 4 & 2 & 5 \\
\hline$\because 1 \%$ & 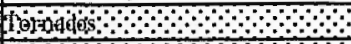 & $\because \because 26$ & $6 \%$ & $\because 3$ & $\because 4 \because$ & $\because \because \because 4$ & $\because 4$ & $\because \because \div$ & $\because \because$ & $\because 6$ \\
\hline$\because 6$ & retip & $\because 4 \%$ & & $\Leftrightarrow$ & $\because 6$ & $\because \because$ & $\because 4:$ & $\because 6$ & $\because 2$ & $\because 4$ \\
\hline$\because 19$ & Gelp & & 1 & & $\because$ & $\because \because 4$ & 65 & $\because 4$ & $\because$ & $\because \because \because$ \\
\hline$\because 20$ & inime & & $\because \div$ & $\because 4 \%$ & $\because 4$ & $\because \because 4$ & $\because \because 6$ & $\because 5$ & $\therefore \because \because 6$ & $\because \because$ \\
\hline$\because 21 \because$ & Teritip & & & $\because \because$ & $\because 4$ & $\because \because 4$ & $\because 5$ & $\because 3$ & 28 & $\because 4$ \\
\hline$\because 22 \%$ & 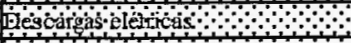 & & & & $\because$ & $\because 4$ & $\because 5$ & $\because$ & $\because$ & $\because 6$ \\
\hline$\because 236$ & & & & 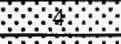 & & $\because 4$ & 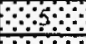 & $5 \%$ & & \\
\hline$\because 24 \because$ & Qrodeso & $\therefore 4$ & $\therefore$ & $\because 2$ & $\because 4$ & $\because 4 \%$ & $\because \because$ & $\because \div$ & $3:$ & $\because 5$ \\
\hline$\because 23$ & Gitopo & & $\because 3:$ & $\because$ & & $\because:$ & $\because 5$ & & & $\because$ \\
\hline 6 & & & & & & & $\because 6$ & & & \\
\hline $37 \because$ & $\because h$ & & $\because 4 \%$ & $\because 30$ & $\because \because \because$ & $\because 6$ & $\because \because$ & $\because 6$ & $\because 16 \because 6$ & $\because \because \because 5$ \\
\hline $28 \%$ & Sibsits & $\because:$ & $\because 3 \because 6$ & $\because 6$ & $\because \%$ & $\because \because 4$ & $\because 4$ & $\because 3$ & $\because \because \cdots$ & $\because 6$ \\
\hline $29 \div$ & Catia & & & & & & & & $\because \because \because \cdots$ & $\because 5:$ \\
\hline
\end{tabular}

Quadro 1 - Ranking dos eventos catastróficos: característicos e impactos.

Obs: As características das catástrofes e seus impactos estão graduados numa escala de 1 (maior) até 5 (menos) 


\section{A especificidade do ambiente tropical}

As regiões situadas entre os trópicos têm, do ponto de vista astronômico, limites rígidos, estabelecidos pelas latitudes de $23^{\circ} 27^{\prime} 33^{\prime \prime}$, ao norte e ao sul do equador, compondo um anel ao redor do globo que abrange $46 \%$ de sua superfície. O significado dessas linhas, é, porém, bem relativo, uma vez que as características da tropicalidade muitas vezes manifestam-se além das mesmas, ou podem, como frequentemente acontece, estar ausentes em seu interior, acrescentando-se o facto de que as regiões tropicais estão longe de serem homogêneas.

O conceito geográfico de região tropical tem sido objeto de amplos debates por parte dos estudiosos, entre os quais citaríamos MARTONNE (1936) e GOUROU (1948), defensores do uso do termo tropical exclusivamente para as regiões quentes e úmidas, ao passo que DEMANGEOT (s/d), PLANHOL et ROGNON (1970), estenderam-no, também, às quentes e áridas. Os geógrafos brasileiros, desde os anos 50, vêm apresentando contribuições significativas para a discussão do tema. SILVEIRA $(1951,1952)$ e PENTEADO (1965) alinharam-se com os dois primeiros autores citados aplicando, portanto o termo tropical como indicativo de ambiente onde dominam o calor e a umidade. Mais tarde, STERNBERG (1971) e AB'SÁBER (1988), além de vários outros, ofereceram subsídios importantes. O assuntoé polêmico não sendo objeto deste trabalho retomar a discussão. Tomaremos o conceito no seu sentido lato, aplicando o termo tropical às regiões situadas em baixas latitudes, sejam secas ou úmidas.

A posição privilegiada da faixa intertropical em relação ao recebimento da radiação solar, faz concentrar o calor nessas latitudes, dotando-as de um excedente energético muito significativo sobre o restante do planeta. Estimativas feitas por HOUGHTON (1954) indicam que esse superavit é, no mínimo, cinco vezes maior que o recebido pelas latitudes altas, consideradas como tais, aquelas situadas além de $60^{\circ}$. A diferençaentre terrase águas quanto a capacidade de absorção e retenção da radiação solar, ou seja a diferença de calor específico, concorre para que o calor latente se concentre nos oceanos e, como a zona intertropical é dominantemente líquida (aí estão apenas $24 \%$ das terras emersas), o fluxo dessa energia chega a ser, aí, três vez superior ao dos mares das latitudes elevadas. Essa importante concentração de calor é dado preliminar para o entendimento da natureza tropical.

As elevadas temperaturas médias constituem uma das peculiaridades dessa faixa, e porém, o dado mais significativoé sua pequena variação anual. A isotermia (amplitude térmica anual inferior a $6^{\circ} \mathrm{C}$ ) é uma característica indissociável da tropicalidadde e está presente mesmo em condições muito diferentes de latitude, altitude, distância do oceano ou regime pluviométrico. Comparemos alguns dados de quatro localidades de latitudes equivalentes, a primeira em alta montanha (Quito, Equador), a segunda, em região sublitorânea (Belém, Brasil), a terceira, em uma planície interior, a $1.400 \mathrm{~km}$, em linha reta, da costa e a quarta em região desértica (v. quadro 2 ):

Se, do ponto de vista térmico, a variação anual é pouco expressiva, o oposto ocorre com a pluviosidade, registrando-se, entre os trópicos, valores muito contrastantes, não só quanto aos totais anuais como quanto ao regime pluviométrico. Este é muito importante e constitui elemento determinante do mecanismo natural intertropical uma vez que as temperaturas oscilam pouco. É fundamental, por exemplo, para a vida vegetal e animal.

Em macro-escala a sazonalidade das chuvas é controlada pelo movimento aparente do sol, de um trópico a outro, correspondendo, a estação chuvosa, à proximidade do sol do ponto zenital. Em latitudes muito baixa (inferiores a $8^{\circ}$ ), em climas úmidos, ocorrem dois máximos coincidentes, aproximadamente com os equinócios e oscilação sazonal da Zona de Convergência Intertropical (ZCIT), ao mesmo tempo que não apresentam estação seca bem caracterizada. Um bom exemplo é Padang (Indonésia, lat. 0056'S) com uma média anual de precipitação de $4.231 \mathrm{~mm}$ e dois máximos, em abril (363 mm) e novembro (518 $\mathrm{mm}$ ), este último um pouco deslocado em relação ao equinócio de primavera. Nas regiões áridas, onde a variabilidade anual e espacial da precipitação é muito grande, torrencialidade constitui a característica mais importante. (Consideramos como torrencial aquela que supera $50 \mathrm{~mm}$ em $60 \mathrm{~mm}$, em geral causadoras de grandes calamidades).

\begin{tabular}{|l|l|r|r|c|c|c|c|}
\hline & Alt. $(\mathrm{m})$ & latitude & $\begin{array}{c}\text { t. mês } \\
+ \text { quente }\end{array}$ & $\begin{array}{c}\text { t. mês } \\
+ \text { frio }\end{array}$ & $\begin{array}{c}\text { amplit. } \\
\text { anual }\end{array}$ & $\begin{array}{c}\text { pluviosid. } \\
\text { anual (mm) }\end{array}$ \\
\cline { 2 - 8 } & Quito (Equador) & 2.875 & $00^{\circ} 13^{\prime} \mathrm{S}$ & $14,8^{\circ} \mathrm{C}$ & $13,7^{\circ} \mathrm{C}$ & $1,1^{\circ} \mathrm{C}$ & 1.110 \\
\cline { 2 - 8 } & Belém (Brasil) & 0 & $01^{\circ} 27^{\prime} \mathrm{S}$ & $26,7^{\circ} \mathrm{C}$ & $25,5^{\circ} \mathrm{C}$ & $2,2^{\circ} \mathrm{C}$ & 2.893 \\
\cline { 2 - 8 } $\begin{array}{r}\text { Quadro 2 - Dados } \\
\text { comparativos. }\end{array}$ & Manaus (Brasil) & 71 & $03^{\circ} 08^{\prime} \mathrm{S}$ & $27,5^{\circ} \mathrm{C}$ & $26,0^{\circ} \mathrm{C}$ & $1,5^{\circ} \mathrm{C}$ & 2.286 \\
\hline $\begin{array}{r}\text { (org. por CoNTI, J.B.) } \\
\text { Mogadíscio (Somália) }\end{array}$ & 12 & $02^{\circ} 02^{\prime} \mathrm{N}$ & $29,0^{\circ} \mathrm{C}$ & $25,5^{\circ} \mathrm{C}$ & $3,5^{\circ} \mathrm{C}$ & 426 \\
\hline
\end{tabular}


A interação oceano $x$ atmosfera concorre de forma importante para definir o mosaico pluviométrico das baixas latitudes e este, por sua vez, constitui, aí, o elemento determinante das variações ambientais, incluindo as calamidades naturais.

O giro anticiclónico da massa oceânica conduz as águas frias, oriundas das latitudes mais elevadas, para as costas ocidentais dos continentes, produzindo dissimetrias muito significativas quanto à distribuição das chuvas. Tais diferenças podem ser acentuadas pelo relevo, quando efeitos orográficos de barlavento ativam a pluviosidade, como no litoral do sudeste brasileiro, onde, em alguns pontos, precipitam-se, mais de $4.000 \mathrm{~mm}$ anuais (é o caso de Paranapiacaba, situada na linha de crista da Serra do Mar, entre São Paulo e Santos) ou, ao contrário, criando "bolsões" secos em áreas situada à sotavento. A região do Chaco boliviano, à "sombra" da Cordilheira dos Andes, recebe menos de $500 \mathrm{~mm}$ anuais de chuvas.

O padrão anticiclónico da circulação atmosférica contribui, também, para salientar os contrastes. A atuação da zona de convergência dos alísios e das macro-células da baixa pressão ("doldrums") em torno da latitude zero fazem aparecer extensos campos de instabilidades, exacerbando a chuva, sobretudo nas áreas oceânicas intensamente bombardeadas pela radiação solar, onde a temperatura das águas superficiais é elevada. No sentido inverso agem os anticiclones semi-estacionados nas latitudes entre 20 e $35^{\text {a }}$ que, por serem semipermanentes, geram extensas superficies de estabilidade.

Naturalmente o excedente de energia da faixa entre os trópicos acelera o processo de evaporação, de tal forma que, aproximadamente, até a latitude de $20^{\circ}$, o volume de água evaporada é quase dez vezes superior à verificada nas latitudes médias. Nas áreas continentais de atmosfera estável (anticiclónicas) onde a reposição de água é insuficiente para restabeleceer o equilíbrio hídrico, a consequência é o surgimento da aridez. $\mathrm{O}$ anel intertropical exibe, portanto, uma enorme variedade de ambientes, desde o superúmido até o rigorosamente árido.

\section{Calamidades pluviométricas no Brasil}

Nove décimos do território brasileiro apresentam clima tropical úmido, ou seja, temperaturas médias do mês mais frio sempre superiores a $18^{\circ} \mathrm{C}$ e médias anuais de precipitação acima de $1.300 \mathrm{~mm}$, características que concorrem para que as calamidades naturais sejam predominante de ordem climática, especialmente aquelas ligadas ao excesso ou escassez de chuvas.

Nas grandes áreas urbanas, especialmente em São Paulo, Rio de Janeiro e Salvador, a estação chuvosa (outubro a março) frequentemente registra episódios calamitosos de inundações com impressionantes danos materiais e humanos. A situação socio-económica da população brasileira exibe enormes contrastes de distribuição de renda com uma parcela muito expressiva vivendo em condições de pobreza. Os dados macro-económicos comparativos entre Brasil e Portugal indicam que o primeiro tem um Produto Interno Bruto de-US\$767.568 milhões e o segundo US\$106.391 milhões. Contudo, a renda "per capita" apresenta uma situação muito desfavorável para o Brasil. Enquanto, no país europeu é de US\$10.670, no sul-americano é de US $\$ 4.630$, ou seja, menos da metade (dados de 1998).

No plano espacial, as diferenças entre riqueza e pobreza aparecem de forma nítida nas maiores cidades, para onde migram os sem trabalho, procedentes das áreas muito deprimidas economicamente. Aí vão construir suas precárias moradias, justamente nos sítios de maior risco como as encostas instáveis e as planícies sujeitas a inundações. As "favelas" ocupam, hoje, centenas de quilômetros do perímetro urbano de todas as grandes cidades brasileiras, constituindo um agudo problema social e ambiental. A capacidade de se defender contra qualquer tipo de calamidade natural dessas populações é mínima e os exemplos que a seguir mostramos, revelamesse alto grau de despreparo.

Entre os dias 19 e 22 de fevereiro de 1988, a área urbana do Rio de Janeiro foi castigada por $384 \mathrm{~mm}$ de chuvas, metade dos quäis $(192 \mathrm{~mm})$ precipitadas só na noite de 19 para 20 . Em anos normais, o mês de fevereiro não registra mais que $140 \mathrm{~mm}$ em seus 28 dias, o que dá idéia da força e torrencialidade do fenômeno de 1988. As consequências dessa calamidade meteorológica, uma das maiores que já assolou o Rio de Janeiro, foram trágicas: encostas desmatadas e de subsolo mal consolidado deslizaram com violência provocando destruições e morte numa escala avassaladora. Casas e edifícios desabaram, logradouros públicos ficaram submersos por espessas camadas de lama e pedra, deixando um saldo de 277 mortos, 735 feridos e mais de 12.000 desabrigados.

No dia 13 de fevereiro de 1996, em caso relatado pela pesquisadora Ana Maria de Paiva Macedo Brandão, da Universidade Federal do Rio de Janeiro, precipitaram-se $200 \mathrm{~mm}$, provocando 38 deslizamentos em encostas, muitas delas ocupadas por barracos e casebres, provocando, por consequência inúmeras vítimas (BRANDÃO, 1997).

Em Salvador, cidade situada, em sua maior parte, sobre colinas areníticas e rochas pouco consolidadas, registraram-se, no dia 27 de abril de 1971, $367 \mathrm{~mm}$ de precipitação, episódio classificado pela UNDRO (United Nations Disasters Rewliefs) como uma das maiores catástrofes mundiais do gênero. produzindo 104 mortos, 1.400 desabamentos e 7.000 desabrigados (GONÇALVES, op. cit.). 
São Paulo, embora seja a maior aglomeração urbana brasileira, não terá seus eventos calamitosos relatados neste artigo por já terem sido objeto de análise por parte do Prof. Jurandyr Luciano Sanches .Ross, em trabalho publicado na revista Territorium em 2001 (ROSS, 2001).

Quase todos esses episódios catastróficos de precipitação estão associados à atuação de sistemas frontais procedentes de latitudes médias e sua interconexão com a Zona de Convergência Intertropicais além de outras causas, como por exemplo, situações sinóticas de oclusão, agravadas por intensa circulação atmosférica de origem oceânica, com alto teor de umidade relativa. Tratando-se de áreas costeiras, interfere, ainda, significativamente, a elevada temperatura da superfície do mar, estimulando a instabilidade atmosférica.

Acrescentaríamos mais um exemplo de catástrofe pluvial, porém, desta vez, fora das áreas metropolitanas.

Na primeira semana de janeiro de 2000 , um trecho doSudeste Brasileiroocupado pela Serrada Mantiqueira e vale médio do rio Paraíba do Sul, entendendo-se pelos estados de São Paulo, Minas Gerais e Rio de Janeiro foi assolado por uma chuva muito intensa, com repercussões que se estenderam por mais de 20.000 quilômetros quadrados. A região havia sido intensamente desmatada nas décadas anteriores e, emfunção disso, toda a tessitura ecológica se desestabilizou, desencadeando escorregamentos de encostas, obstruçãode vales, enchentes e destruições de excepcional magnitude. A localidade de Passa Quatro, no sul de Minas Gerais, registrou, nos primeiros quatro dias de janeiro, 600,6 mm de chuvas, sendo que só no dia 3, precipitaram-se $322,6 \mathrm{~mm}$ e, na mesma data, em São Lourenço, situada $60 \mathrm{~km}$ ao norte, os pluviômetros assinalaram $171,0 \mathrm{~mm}$. O balanço oficial da tragédia registrou mais de 80.000 desabrigados, além de 8 mortos.

Tal excepcionalidade meteorológica foi determinada pelo estacionamento da frente polar atlântica sobre a área durante três dias, documentada por imagens do satélite GOES e cartas sinóticas de superfície, tendo o fenômeno se agravado pela presença, na região, de uma massa de ar previamente instabilizada pela frente fria antecedente. $\mathrm{O}$ alinhamento geral do relevo (SO-NE), perpendicular ao avanço das massas úmidas, concorreu para estimular, potencializar, o efeito orográfico, ampliando o fenômeno pluvial. Mais uma vez, ouso predatório do meio, desflorestando$-o$, sem nenhum controle, provou uma calamidade de grandes proporções.

\section{Riscos de desertificação}

Cerca de 1/10 do território brasileiro, ou seja, aproximadamente 850.000 quilómetros quadrados, apresenta insuficiências de chuvas, ou seja médias anuais inferiores a $800 \mathrm{~mm}$., insolação média de 2.800 horas/anoe evaporação média anual elevadíssima, da ordem de $2.000 \mathrm{~mm}$. Trata-se de um "bolsão" seco no Nordeste do país, onde ocupa a maior parte dos territórios interiores e um pequeno trecho do litoral. As precipitações são escassas e irregulares, apresentado alta variabilidade interanual e acentuados contrastes espaciais. Ocupada desde século XVI, quando se iniciou a colonização portuguesa, a região apresenta, atualmente, densidade demográfica acima de 30 habitantes por quilômetros quadrado, valor alto para padrões brasileiros, sendo as condições climáticas muito adversas para a prática da agricultura.

A pecuária extensivaé, tradicionalmente, a atividade econômica mais difundida, porém os rendimentos são baixos e os índices de pobreza os mais críticos do país.

Nesse contexto, são as grandes secas que constituem os maiores riscos naturais porque podem induzir o processo de desertificação e ompobrecimento generalizado.

A conferência das Nações Unidas sobre o Meio Ambiente e Desenvolvimento realizada em 1992, no Rio de Janeiro, conceituou a desertitificação como sendo "a degradação das terras áridas, semi-áridas e subúmidas resultantes de vários fatores, incluindo variações climáticas e atividades humanas".

É o que vem ocorrendo em vários trechos do domínio semi-árido brasileiro onde a ocupação predatória esta a produzir ambientes muito degradados, isto é, verdadeiros desertos ecológicos, originados da pressão intensa das atividades econômicas sobre ecossistemas frágeis.

Entre 1992 e 1995 realizamos, naquela região, pesquisa utilizando a metodologia do tratamento estatístico de séries temporais para verificação de tendências, analisando dadós de 237 postos pluviométricos, todos com dimensão superior a 50 anos. A tendência, que em termos estatísticos se define como a função do valor médio de seu processo gerador, expressa-se pela reta de mínimos quadrados, definida pela equação $\mathbf{y}=\mathbf{b} . \mathbf{x}+\mathbf{a}$, onde a representa $\mathbf{o}$ coeficiente linear da reta e $\mathbf{b}$ o coeficiente angular ou taxa de variação anual, segundo a técnica da regressão linear, sendo a significância expressa em milímetro/ /ano. O resultado assinalou a presença de pelo menos três áreas com retas de tendência negativa, as quais interpretamos como sendo "bolsões" de desertificação: região sul-ocidental do Estado do Ceará, conhecida como "sertão dos Inhamuns", vale do rio SãoFrancisco, entre Paulo Afonso e Propriá e vale médio do mesmo rio, entre Bom Jesus da Lapa e Xique-Xique, além de manchas menos expressivas nos Estados do Rio Grande do Norte, Paraíba e Pernambuco (CONTI, 1995). 


\section{Conclusão}

Fora das grandes áreas sísmicas do globo, o imenso território brasileiro não apresenta vulcões ativos ou riscos de terremotos de grandes proporções, ao mesmo tempo que se encontra distante das rotas dos ciclones tropicais, não registrando, episódios de vendavais calamitoṡos. Mesmo as turbulência de menor expressão espacial, como os tornados, são escassamente registrados, não constituindo risco de categoria elevada.

São portanto os fenômenos de natureza pluviométrica que castigam o país, seja pelo excesso, especialmente em áreas intensamente urbanizadas ou que foram ocupadas de forma predatória, seja pela escassez, na região nordestina afetada pelas baixas médias pluviométricas.

A condição de tropicalidade agrava as consequências em virtude do elevado potencial energético envolvido nos fenômenos naturais, os quais acabam provocandograndes tragédias ambientais e humanas.

A sociedade brasileira, em virtude de suas carências, especialmente de ordem tecnológica e econômica, ainda não demonstrou ser capaz de superá-las com sucesso.

\section{Referências bibliográficas}

AB'SÁBER,AN. (1988)-Espaço Territorial e ProteçãoAmbiental. São Paulo, Ed. Marco Zero/Associação dos Geógrafos Brasileiros nº 3, p. 9-31.

BRANDÃO, AM.P. M. (1997) - As Chuvas e a Ação Humana: uma Feliz Coincidência. Seminário: Proteçãoe Controledos Efeitos dos Temporais no Rio de Janeiro. Universidade Federal do Rio de Janeiro, p. 21-37.

BRYANT, E. A (1993) - Natural Hazards. Cambridge University, p. 9.

CONTI, J. B. (1988) - O Meio Ambiente Tropical. Associação de Geografia Teorética. Geografia, vol 14, nº 28, p. 69-79.

CONTI, J. B. (1995) - Desertificação nos Trópicos. Proposta de Metodologia de Estudo Aplicada ao Nordeste Brasileiro.
Tese de Livre-Docência apresentada à Faculdade de Filosofia, Letras e Ciências Humanas da Universidade de São Paulo, $208 \mathrm{p}$.

DEMANGEOT, J. (s/d) - Les milieux naturèls désértiques. Paris. Centre de Documentation Universitaire. $300 \mathrm{p}$.

GONÇALVES, N.M.S.(1992)-Impactos Pluviaise Desorganização do Espaço em Salvador/Baia. Tese de Doutoramento apresentada à Faculdade de Filosofia, Letras e Ciências Humanas da Universidade de São Paulo, 268 p.

GOUROU, P. (1948) - Les Pays Tropicaux. Principes d'une Géographie Humanine et Economique. Paris, Presses Universitaires de France, $196 \mathrm{p}$.

HOUGHTON, H. G. (1954) - On the Annual Heat Balance of Northern Hemisphere. Journal of Meteorology, february, p.1-9.

PENTEADO, A R. (1965) - Uma Interpretração do Mundo Tropical Baseada nas Condições de sua Geografia Física. São Paulo, Instituto de Geografia da Universidade de São Paulo. Orientação n $^{\circ}$ 1, p 51-54.

PLANHOL et ROGNON (1970) - Les Zones Tropicales Arides et Subtropicales. Paris. Librairie Armand Colin, 487 p.

REBELO, F. (2001) - Riscos Naturais e Acção Antrópica. Coimbra. Imprensa da Universidade, $274 \mathrm{p}$.

ROSS, L. L. S. (2001) - "Inundações e Deslizamentos em São Paulo. Riscos da Relação Inadequada Sociedade-Natureza". Territorium. Revista de Geografia Física Aplicada no Ordenamento do Território e Gestão de Riscos Naturais. MinervaCoimbra, p. 15-23.

SILVEIRA, J. D. da (1951) - Considerações em Torno da Geografia Tropical.São Paulo. Associação dos Geógrafos Brasileiros. Boletim Paulista de Geografia ${ }^{\circ}$ 4, p. 5-44.

SILVEIRA, J. D. da (1952) - Baixadas Litorâneas Quentes e Úmidas. SãoPaulo. Boletim da Faculdade de Filosofia, Ciências e Letras da Universidade de São Paulo, $n^{\circ} 152$, colecção Geografia $n^{\circ} 8,224$ p.

STERNBERG, H. O'REILLY (1971) - A Terra e o Homem nos Trópicos. São Paulo. Instituto de Geografia da Universidade de São Paulo. Colecção Caderno de Ciências da Terra n ${ }^{\circ} 12$, $15 \mathrm{p}$. 